\author{
А.А. Кдырбаева ${ }^{1}$ Е.В. Рябова ${ }^{l}$, А.С. Стамбекова ${ }^{l}$ \\ ${ }^{1}$ КазНПУ им. Абая, Алматы, Казахстан

\section{СОВЕРШЕНСТВОВАНИЕ КАЧЕСТВА ОБРАЗОВАНИЯ ПОСРЕДСТВОМ РАЗВИТИЯ ИССЛЕДОВАТЕЛЬСКОЙ КОМПЕТЕНТНОСТИ ПЕДАГОГА \\ (Опыт работы ОСШ г. Алматы)}

\begin{abstract}
Аннотация
В статье с позиций современной педагогической науки, на основе анализа имеющихся исследований проблемы совершенствования качества образования, раскрывается характеристика компонентов, составляющих сущность исследовательской компетентности педагога, которые формулируются как мотивационно-ценностный, когнитивный и содержательный компоненты.

Оценка качества подготовки будущего учителя начинается с оценки самой личности. Роль обучения при этом сводится к обеспечению становления такой личности, которая способна создать качественные изменения в сфере своей профессиональной деятельности. Отсюда следует, что учитель, который сам постоянно учится, имеет возможность самостоятельно поднять уровень обучения, поэтому обучающегося следует рассматривать как объект и субъект управления.

Ключевые слова: педагог, исследовательская компетентность, исследовательская культура, учитель новой формации, мотивация.
\end{abstract}

\author{
А.А. Кдырбаева ${ }^{1}$, Е.В. Рябова ${ }^{l}$, А.С. Стамбекова ${ }^{l}$ \\ ${ }^{1}$ Абай атындавы ҚазҰПУ, Алматы, Қазақ̧стан

\section{ПЕДАГОГТЫҢ ЗЕРТТЕУ ҚҰЗЫРЕТТІЛІГІН ДАМЫТУ АРҚЫЛЫ БІЛІМ БЕРУ САПАСЫН ЖЕТІЛДІРУ \\ (Алматы қаласындағы ЖББМ жұмыс тәжірибесі)}

\begin{abstract}
Аңңдатпа
Мақалада қазіргі педагогикалық ғылым тұрғысынан, білім беру сапасын жақсарту мәселесін қолда бар зерттеулерді талдау негізінде мұғалімнің зерттеу құзіреттілігінің мәнін құрайтын компоненттердің сипаттамалары ашылады, олар мотивациялық-құндылық, танымдық және мазмұнды компоненттер ретінде тұжырымдалады.
\end{abstract}

Болашақ мұғалімнің дайындық сапасын бағалау жеке тұлғаны бағалаудан басталады. Бұл жағдайда оқытудың рөлі өзінің кәсіби қызметі саласында сапалы өзгерістер жасай алатын осындай тұлғаның қалыптасуын қамтамасыз ету болып табылады. Демек, үнемі оқитын мұғалімнің оқу деңгейін өз бетінше көтеруге мүмкіндігі бар, сондықтан білім алушыны басқару объектісі және субъектісі ретінде қарастырған жөн.

Түйін сөздер: педагог, зерттеу құзыреттілігі, зерттеу мәдениеті, жаңа формация мұғалімі, мотивация.

\author{
A.A. Kdyrbaeval, E.V. Ryaboval ${ }^{l}$, A.S. Stambekova ${ }^{l}$ \\ ${ }^{1}$ KazNPU named after Abai, Almaty, Kazakhstan
}

\title{
THE IMPROVING THE QUALITY OF EDUCATION THROUGH THE DEVELOPMENT OF RESEARCH COMPETENCE OF THE TEACHER (Experience of the OSH in Almaty)
}

\begin{abstract}
In the article, from the standpoint of modern pedagogical science, based on the analysis of existing research on the problem of improving the quality of education, the characteristic of the components that
\end{abstract}


make up the essence of the research competence of the teacher, which are formulated as motivational-value, cognitive and content components, is revealed.

Assessment of the quality of training of a future teacher begins with an assessment of the personality itself. The role of training in this case is to ensure the formation of such a person who is able to create qualitative changes in the sphere of their professional activity. It follows that a teacher who is constantly learning himself has the opportunity to raise the level of learning independently, so the student should be considered as an object and subject of management.

Keywords: teacher, research competence, research culture, teacher of a new formation, motivation.

Введение. На сегодняшний день в казахстанской образовательной системе одним из приоритетных направлений является соответствие высоким стандартам и требованиям, предъявляемым к качеству высшего образования во всем мире. В связи с этим стратегической целью современного образования Республики Казахстан является создание наиболее благоприятных условий для формирования поликультурной, высокообразованной, толерантной, готовой к творчеству, конкурентоспособной личности.

Очевидно, что в рамках учебных программ традиционного формального образования не представлялось возможным воспитание и развитие личности с таким набором качеств. Выходом из создавшегося положения по общему признанию и зарубежных и отечественных исследователей была перестройка образования, в такой его организации, которая обеспечит компетентностное образование, ориентированное на результат.

В контексте реализации указанной задачи основной вектор образовательной деятельности направлен на развитие у обучающихся таких важных личностных качеств, как самостоятельность, инициатива, познавательная активность, творческие способности и навыки самостоятельного поиска знаний и умений, необходимых для их дальнейшего применения в самостоятельной практической деятельности.

Из вышесказанного следует, что формирование у обучающихся такого качества, как «исследовательская компетентность», способствует успешной реализации образовательных задач, поставленных перед обществом.

Анализ публикаций по теме исследования. Проблемой формирования и развития профессиональной компетенции педагогов занимались многие зарубежные и отечественные ученые. В российской науке эти вопросы разрабатывали В.В. Байденко, И.А. Зимняя, А.К. Маркова, В.А. Сластенин, А.И. Савенков, в Казахстане - М.Ж. Жадрина, К.Ж. Аганина, Б.К. Игенбаева, А.А. Кдырбаева, Е.В. Рябова $[2,3,4,5,6,7,8]$ и другие. Констатируя выводы этих исследований с позиции принципов личностно-деятельностного, компетентностного подходов, можно отметить, что школе нужен педагог, умеющий видеть целостную проблему в практике обучения и воспитания учащихся, владеющий навыками анализа собственной деятельности с применением объективных, научно обоснованных методов. Следовательно, основной целью профессионального образования является воспитание и развитие личности учителя, которая способна непрерывно повышать общетеоретический и профессиональный уровень.

Исходя из этой концепции, на основе инновационных подходов к усовершенствованию подготовки и переподготовки учительских кадров, была построена работа в средней школе № 76 города Алматы.

Методология исследования. Методологической основой исследования послужили положения теории личности, теории освоения деятельности (Л.С. Выготский, А.Н. Леонтьев, С.Л. Рубинштейн и др.); теории формирования исследовательских умений (В.А. Сластенин, М.Г. Ярошевский); теоретические положения о научно-исследовательской деятельности (А.М. Новиков, И.А. Хоменко).

В качестве основных методов исследования выбраны: теоретический анализ психолого- педагогической литературы по указанной проблеме исследования, беседа, наблюдение, анализ состояния практики и сопоставление данных с социальными требованиями, изучение нормативных документов.

Результаты исследования. Необходимо отметить, что исследовательская компетентность достигается в процессе деятельности, направленной на получение субъективно нового знания посредством проведения обучающимися самостоятельного исследования.

Любое проявление самостоятельности, как одного из видов деятельности, основывается на наличии мотивационной составляющей. Ученые справедливо подчеркивают, что любая деятельность направлена на определенный предмет, который и является мотивом, т.е. внутренней побудительной 
силой, заставляющей субъекта заниматься той или иной деятельностью.

Эти положения отражены в работах П.Ф. Каптерева, который утверждал: «Только тогда поступки имеют нравственную и педагогическую ценность, когда они выражают соответствующие внутренние процессы, когда они искренне и разумно мотивированы» [12, с.87]. Из этого следует, что выполнению любого вида деятельности предшествует возникновение мотива, побуждающего на ее выполнение, а любая мотивированная деятельность представляет собой определенного рода ценность для субъекта, ее выполняющего.

Таким образом, в качестве первого компонента исследовательской компетентности субъектов мы рассматриваем мотивационно-ценностный компонент, который характеризуется отношением субъекта к деятельности как к ценности; пониманием и переживанием ее значимости; интересом к деятельности и касающимся ее вопросам; увлеченностью саморазвитием и стремлением к самосовершенствованию.

Мотивационно-ценностный компонент включает в себя: систему знаний, убеждений, потребностей и мотивов, интересов и отношений, организующих и направляющих волевые усилия личности, познавательную и практическую деятельность по овладению ценностями, нацеленность на самосовершенствование. Ученые полагают, что сущность мотивационно-ценностного компонента заключена в возможности формирования у субъекта осознанной потребности в осуществлении выполняемой деятельности.

С нашей точки зрения, мотивационно-ценностный компонент раскрывается через творческое отношение и интерес обучающихся к постижению будущей профессии, ориентацию на достижение высоких результатов в профессиональной деятельности, систему смыслов личности, уровень ее целей, притязаний и потребностей.

Проявляя исследовательскую самостоятельность, обучающиеся осуществляют поиск личностного смысла выполняемой ими деятельности, ее ценности и значимости; проходят и осознают путь самостоятельного научного поиска, творческих решений и открытий; осознают самостоятельно найденную научную истину как ценность.

Приоритетными мотивами обучающихся являются: потребность в овладении исследовательскими знаниями и умениями, готовность к их применению в процессе проявления исследовательской самостоятельности; стремление к профессиональному саморазвитию и интеллектуальному самосовершенствованию, к высокой самоактуализации и успешной самореализации личностно-творческого потенциала будущего специалиста, профессионала своего дела.

Очевидно, что исследовательская самостоятельность не может быть проявлена без наличия у обучающихся специальных знаний и умений, необходимых для выполнения исследовательской деятельности.

Этот факт явился основополагающим в контексте определения нами следующего содержательного компонента исследовательской компетентности - когнитивного. Когнитивный компонент характеризуется совокупностью предметных, методических и технологических знаний, интегрирующихся в общие и специальные знания, необходимые для выполнения конкретного рода деятельности.

Целью когнитивного компонента, по мнению ученых, является приобретение субъектом знаний, умений и навыков, необходимых ему для выполнения определенного рода деятельности, а также знаний методов и способов, необходимых субъекту для их формирования. В качестве очередного компонента исследовательской компетентности мы рассматриваем содержательный компонент, который является теоретическим фундаментом, включающим в себя не только систему необходимых знаний и умений, но и способность их приобретения.

Характеристикой содержательного компонента, по нашему мнению, является определение для обучающегося необходимого для усвоения базового набора теоретического и практического инструментария, представленного в виде сгруппированных по своему назначению и содержанию соответствующих знаний, умений и навыков.

Дискуссия. Сегодня мы говорим об учителе, как творческой индивидуальности, который имеет оригинальное педагогическое мышление, критическое мышление. Современный педагог - исследователь, создатель новых программ, технологий, методик, способный интерпретировать информацию в новых педагогических условиях на основе диагностики целеполагания и рефлексии [11].

Стратегию педагогического образования составляют развитие и саморазвитие личности, способной свободно ориентироваться в сложных социокультурных обстоятельствах, ответственно и профессионально действовать в соответствии с требованиями современности. Эта позиция очень 
четко определена в работах В.А. Сластенина. Так, он пишет: « Становясь центральным феноменом культуры, современное образование ориентируется на утверждении личностного, сущностного начала в человеке. То есть на такую личность, которая не только владеет определенной суммой знаний, но и способна к дальнейшему совершенствованию, саморазвитию, самореализации. Налицо новая тенденция, связанная с приоритетом человеческого начала, требующая формирования новых гуманистически ориентированных, гуманитарных подходов к воспитанию современных специалистов» [2].

Основное противоречие в образовательном процессе сегодня проявляется в отношениях «старого» и «нового», т.е. традиционного и инновационного. Развитие образовательного процесса обеспечивают, с одной стороны, нововведения, с другой - обязательные устойчивые компоненты, которые впоследствии складываются в педагогические традиции.

В связи с этим одной из важнейших становится проблема формирования нового педагогического сознания. Именно мировоззрение, как система принципов, ценностей, идеалов и убеждений, ведущих направление деятельности и отношение к действительности, определяет выбор специалистом той или иной методологии и теоретической концепции, обуславливающей пути и способы ее реализации на практике.

Мировоззрение как основополагающее личностно-профессиональное качество специалиста имеет еще один немаловажный аспект: порождаемые им глубинные установки проецируются учителем (сознательно или бессознательно) не только на сущность педагогического процесса, на других участников педагогического взаимодействия, но и на собственную личность.

В школе №76 города Алматы на постоянной основе проводится семинар, на котором обсуждаются вопросы поиска новых форм организации и социализации учебного процесса, доведения до слушателей алгоритма проведения исследования, его основополагающих этапов, рекомендаций источников и обзора необходимой для изучения научной литературы. Коллектив педагогов школы исходит из того, что педагогическое самообразование и научно-методическая, исследовательская работа являются необходимыми факторами ее оптимального функционирования и развития. И ее назначение - совершенствование профессионального мастерства педагогического коллектива.

Базовыми функциями научно-методической работы данной школы являются:

- Информационно-инструктивная, обучающая функция;

- Оказание помощи педагогам в научном осмыслении и проектировании своей педагогической деятельности, ее перспектив, путей совершенствования;

- Обобщение, пропаганда и распространение передового педагогического опыта;

- Стимулирование педагогического самообразования и педагогического творчества администрации и учителей.

Основной элемент педагогического творчества учителя в современной школе, показатель ответственности, способностей и таланта - это исследовательская деятельность педагога. Исследовательский творческий поиск, отмечает А.И. Савенков, важен для человека с двух точек зрения: «с точки зрения получения какого-либо нового продукта и с точки зрения значимости самого процесса поиска.

Человек способен испытывать, и испытывает истинное удовольствие не только от результатов творчества, но и от самого процесса творческого, исследовательского поиска» [5]. А.К. Маркова определяет исследовательскую компетентность как обладание способностью и умениями выполнять определенные трудовые функции [6].

Обязательность формирования и развития исследовательских навыков педагога на сегодняшний момент обусловлено тем, что учение воспринимается как процесс умственного развития обучающихся, а не как процесс запоминания. Помимо этого используется исследовательский и технологический подходы в построении процесса обучения и воспитания, а также формирование устойчивой потребности в саморазвитии.

Учитель в современном педагогическом процессе примеривает новые роли - коуча, тренера, модератора, фасилитатора, которые способствуют:

1. Эффективности реализации жизненных целей, полному раскрытию индивидуальности;

2. Согласованности целей, мотивов и способов действий;

3. Выбору методов и приемов, позволяющих наиболее эффективно достичь целей профессиональной деятельности;

4. Созданию ситуаций освоения учащимися всех стадий рефлексии (самосознания, само- 
определения, самовыражения, самоутверждения, самореализация и саморегуляция).

Для выполнения этих задач педагогу необходимо сделать акцент на развитии исследовательских компетенций. Мы считаем, что именно педагог, обладающий исследовательской культурой, может выступать как ресурс обеспечения качества образования школьников.

Поэтому, для того чтобы сделать процесс развития исследовательской компетентности педагогов более эффективным, перед школой стоят следующие задачи:

- обеспечить обучение педагогов навыкам исследовательской деятельности;

- проводить индивидуальное научно-методическое консультирование;

- осуществлять научное руководство исследовательской деятельности педагога;

- целенаправленно формировать профессиональное самосознание учителя;

- организовывать учебно-воспитательный процесс с учетом влияния объективных условий школы.

В ходе реализации исследовательской деятельности, направленной на раскрытие творческих возможностей учителей (а вместе с тем и учащихся), коллектив столкнулся с определенными трудностями:

- адаптация педагогов к исследовательской деятельности. Определение учителями личной траектории профессионального развития на основе усвоения исследовательских компетенций;

- обеспечение качества образования учащихся, что проявляется;

- в выработке у учащихся навыков самостоятельной рефлексивной деятельности;

- в повышении внутренней мотивации и познавательной активности учащихся;

- в развитии критического мышления, творческих способностей учащихся.

Работа педагогического коллектива школы позволила рассмотреть и систематизировать имеющуюся информацию о профессиональной деятельности учителя, выделить блоки, характеризующие различные стороны педагогической деятельности, уровни профессиональной компетентности и готовности к инновационной (в данном случае исследовательской деятельности) каждого учителя. Ведь решающее значение в подготовке к исследовательской деятельности и дальнейшей профессиональной квалификации учителя имеет не столько объем знаний, сколько их систематичность, подвижность, умение использовать их творчески в измененных условиях работы школы. Наработки по данным вопросам позволяют создавать условия в школе для саморазвития учительского коллектива. Тем более что инновационная, исследовательская, экспериментальная деятельность является средством влияния на педагогический процесс и его результаты, фактором развития школы; инновационная деятельность не дает сиюминутных положительных результатов. Она способствует неординарности и индивидуальности опыта, квалификации педагогического мастерства учителя.

Заключение. Таким образом, данная школа сегодня формирует учителя новой формации, выполняя при этом ряд функций:

- Обучающая функция ориентирована на углубление знаний и развитие навыков специалистов, необходимых для совершенствования их профессиональной деятельности;

- Консультационная функция предполагает оказание помощи педагогу по поводу конкретной проблемы через указание на возможные способы ее решения или актуализацию дополнительных способностей педагога;

- Психотерапевтическая функция имеет своей задачей содействие педагогу в преодолении различного рода психологических барьеров и затруднений, препятствующих успешному осуществлению профессионально-образовательной деятельности;

- Коррекционная функция направлена на изменение реализуемой специалистом модели практической деятельности, а также на исправление допущенных профессиональных ошибок;

- Адаптационная функция обеспечивает согласование ожиданий и возможностей работника с требованиями профессиональной среды и меняющимися условиями трудовой деятельности.

Подводя итоги, можно с уверенностью сказать, что важнейшим условием повышения качества образования является создание условий, активизирующих профессионально-познавательный поиск педагога, способствующий развитию его творческого потенциала, профессиональной компетентности и исследовательской культуры педагогов.

Также можно утверждать, что качество подготовки педагогических кадров в значительной степени зависит от успешного решения вопроса отбора абитуриентов на обучение в педагогическом университете, практической подготовки, трудоустройства и закреплении выпускников на рабочем месте. Очевидно, что главным критерием отбора на педагогические специальности должны быть не 
только глубокие знания по тому или иному предмету, а наличие у будущего педагога необходимых для педагогического труда качеств, черт характера, таких как: уметь видеть и формулировать проблему (в личном и профессиональном плане), находить пути рационального ее решения; грамотно работать с информацией (уметь собирать необходимые факты, анализировать их, делать аргументированные выводы), предотвращать любые конфликтные ситуации и уметь из них выходить, самостоятельно работать над развитием интеллекта, повышением культурного уровня.

Таким образом, качество образования определяется не только объемом знаний, но и параметрами личностного, мировоззренческого, гражданского развития.

Список использованной литературы:

1 Закон Об образовании РК №319-III от 27.07.2007 года с изменениями, внесенными законами РК om 02.07.2018 №165-VI: https://kodeksy-kz.com/ka/ob_obrazovanii/l1.htm

2 Сластенин В.A. Современные подходы к подготовке учителя // Педагогическое образование и наука. - 2000. - №1. - С.75-78.

3 Зимняя И.А. Педагогическая психология. Учебник для вузов. - М.: Логос, 2000. - 384 c.

4 Зимняя И.А. Ключевые компетенции - новая парадигма результата образования // Высшее образование сегодня. - 2003. - №5. - C.34-42.

5 Савенков А.И. Проблема компетентности в педагогической психологии и современном образовании // Педагогика и Психология. - 2010. - №1. - С.17-24.

6 Маркова А.К. Модель профессиональной компетентности учителя в соответствии со стандартами образования // Завуч. - 2001. - №4. - C.113-126.

7 Кдырбаева А.А. Методологические аспекты подготовки будущих специалистов начального образования к профессиональной деятельности // Педагогика и Психология. - 2012. - №1. - С.94-98.

8 Кдырбаева А.А., Рябова Е.В. Формирование профессиональных качеств будущих учителей начальных классов через работу с текстовым материалом // Материаль VII Международной научно-практической конференции «Актуальные проблемы дошкольного и начального образования». - Казань, 2018. - С.367-372.

9 Выготский Л.С. Психология развития ребенка. - М.: Смысл, 2004. - 512 c.

10 Программа развития образования Республики Казахстан 2011-2020 г2. - Астана, 2010.

11 Данильченко В.М. Образование нового времени. http://www.kt-lospo.com/study/obrazovenie novogo vremeni.htm

12 Каптерев П.Ф. Избранные педагогические сочинения: под ред. А.М. Арсеньева. - М.: Педагогика, 1982. - 704 c.

Reference:

1. Law on Education of the Republic of Kazakhstan No. 319-III dated July 27, 2007, as amended by the Laws of the Republic of Kazakhstan dated July 02, 2018 No. 165-VI:https://kodeksykz.com/kalob_obrazovanii/l1.htm

2. Slastenin V.A. Modern approaches to teacher training // Pedagogical education and science. - 2000. No. 1. - S. 75-78.

3. Zimnyaya I.A. Pedagogical psychology. Textbook for universities. - M.: Logos, 2000 .-- 384 p.

4. Zimnyaya I.A. Key competencies - a new paradigm of the result of education // Higher education today. - 2003. - No. 5. - P.34-42.

5. Savenkov A.I. The problem of competence in educational psychology and modern education // Pedagogy and Psychology. - 2010. - No. 1. - P.17-24.

6. Markova A.K. Model of professional competence of a teacher in accordance with educational standards. - 2001. - No. 4. - S. 113-126.

7. Kdyrbaeva A.A. Methodological aspects of training future primary education specialists for professional activity // Pedagogy and Psychology. - 2012. - No. 1. -S.94-98.

8. Kdyrbaeva A.A., Ryabova E.V. Formation of professional qualities of future primary school teachers through work with textual material // Materials of the VII International Scientific and Practical Conference "Actual problems of preschool and primary education." - Kazan, 2018 .-- pp. 367-372.

9. Vygotsky L.S. Child development psychology. - M .: Smysl, 2004 .-- 512s.

10. Program for the development of education of the Republic of Kazakhstan 2011-2020. - Astana, 2010. 


11. Danilchenko V.M. Education of the new time. http://www.kt-
lospo.com/study/obrazovenie novogo vremeni.htm

12. Kapterev P.F. Selected pedagogical works: under the editorship of A.M. Arsenyev. - M .: Pedagogika, $1982 .-704 p$.

МРНТИ 14.39.07

https://doi.org/10.51889/2020-3.1728-5496.03

\author{
Г.Т. Сәдуақ̆асова ${ }^{1}$, С.3. Нишанбаева ${ }^{2}$, А.Т. Туралбаева \\ ${ }^{1}$ Абай атындагы Қазақ ұлттық педагогикалық университеті \\ ${ }^{2}$ Aлматы университеті
}

\title{
ОТБАСЫЛЫҚ-АДАМГЕРШІЛІК ҚҰНДЫЛЫҚТАРДЫН ГЕНЕЗИСІ МЕН КҰРЫЛЫМЫ
}

\begin{abstract}
Аң̧датпа
Бұл мақалада теориялық талдаулар барысында отбасы-адамгершілік құндылықтардың даму эволюциясы және генезисі төрт кезеңге бөлініп жіктеледі. Қазақстандық ғалымдардың еңбектеріндегі «Отбасы» ұғымына контент-талдау (1975-2015 жж.) ұсынылып, «отбасы», «отбасы-адамгершілік құндылықтар» ұғымдарының құрылымы философиялық, тарихи-әлеуметтік, педагогикалық-психологиялық тұрғыдан сипатталады. «Отбасы», «отбасы-адамгершілік құндылықтар» ұғымдарына анықтамалар беріліп нақтыланады. Теориялық-әдіснамалық зерттеулер қоры негізге алынып, ЖОО-дағы студенттердің отбасы-адамгершілік құндылықтарын қалыптастыруға байланысты экспериментті ұйымдастыру алгоритміне сай әдістер бойынша диагностика жұмыстары жүргізілді. Студенттердің «отбасы құндылықтары» жайлы теориялық білімдерінің деңгейін зерттеу мақсатында анықтау эксперименті ұйымдастырылды. Ш.Шварцтың «Құндылық сауалнамасы» әдістемесін жүргізу негізінде сауалнама алынып нәтижесі талданды.

Түйін сөздер: отбасы генезисі, құндылықтар, отбасы-адамгершілік құндылықтар, адамгершілік мінез-құлық, үйлесімділік.
\end{abstract}

\author{
Г.Т. Садуакасова ${ }^{1}$, С.3. Нишанбаева ${ }^{2}$, А.Т. Туралбаева ${ }^{1}$ \\ ${ }^{1}$ Казахский национальный педагогический университет имени Абая \\ ${ }^{2}$ Университет Алмать
}

\section{ГЕНЕЗИС И СТРУКТУРА СЕМЕЙНО-НРАВСТВЕННЫХ ЦЕННОСТЕЙ}

Аннотация
В данной статье в ходе теоретических анализов эволюция и генезис развития семейнонравственных ценностей классифицируются на четыре этапа. Контент-анализ понятия «семья» в трудах казахстанских ученых (1975-2015 гг.) представленная структура понятий «семья», «семейнонравственные ценности» характеризуется философским, историко-социальным, педагогико-психологическим аспектом. Уточняются определения понятий «семья», «семейно-нравственные ценности». На основе фонда теоретико-методологических исследований проведена диагностика по методам, соответствующим алгоритму организации эксперимента в условиях формирования семейнонравственных ценностей студентов вуза. Был организован эксперимент по определению уровня теоретических знаний студентов о «семейных ценностях». На основе проведения методики «анкета ценностей» Шварца был проведен опрос и проанализированы результаты.

Ключевые слова: генезис семьи, ценности, семейно-нравственные ценности, нравственное поведение, гармония. 